\title{
Patient dose from radiographic rejects/repeats in radiology centers of Urmia University of Medical Sciences, Iran
}

\author{
Nasrollah Jabbari $^{{ }^{*}}$, Ahad Zeinali ${ }^{1}$, Leili Rahmatnezhad ${ }^{2}$ \\ ${ }^{1}$ Department of Medical Physics and Imaging, Urmia University of Medical Sciences, Urmia, Iran; \\ *Corresponding Author: njabbarimp@yahoo.com, njabbarimp@gmail.com \\ ${ }^{2}$ Department of Midwifery, Urmia University of Medical Sciences, Urmia, Iran
}

Received 3 November 2011; revised 3 December 2011; accepted 16 December 2011

\begin{abstract}
Medical diagnostic X-rays are the largest manmade source of ionizing radiation received by the members of the general public. The aim of this study was to evaluate the radiographic reject/repeat rate and also to determine dose to the patients from radiographic rejects/repeats in radiology centers of Urmia University of Medical Sciences. During a 4 month period the most frequently examinations were chosen in three radiology centers. A form was designed as a reject/repeat analysis form for radiographers to complete each time a film was rejected by radiologists or repeated. The collected data were compiled at the end of each week and entered into a computer for analysis at the end of study. The results of this study showed that highest and lowest repetition rates were for pelvis, $14.01 \%$ and upper limb, $4.17 \%$, respectively. The main reasons of repetition of radiographs were due to exposure (54\%) and positioning (18\%) errors. The average repeat rate in all three hospitals was $\mathbf{7 . 2 0 \%}$. It was found that human error has important role to repetition of radiographs. It is demonstrated that those patients having repeated radiographs received an average of 3.23 $\mathrm{Gy} \cdot \mathrm{cm}^{2}$. Based on the findings of this study it must be remembered that the highest repetition rate was for pelvis. Considering the radiosensitive organs related to pelvis especially in pediatric patients some special considerations must be applied for pelvis examinations.
\end{abstract}

Keywords: Patient Dose; Radiography; Exposure; Repeat Rate

\section{INTRODUCTION}

Medical imaging provides valuable information with regard to normal and diseased anatomy that can occur within the human body. As we know an important goal in radiography is to obtain the best diagnostic information by delivering the least radiation dose to the patient [1]. On the other hand, radiology is a most valuable aid to diagnosis when employed in accordance with the general health needs of the individual patient, but its use should be tailored to the needs of that patient [2].

The use of ionizing radiation in medical imaging contributes the largest amount of man-made exposure to the public [3]. It has been estimated that about $21 \%$ of the total somatic dose and about $10 \%$ of the total genetically significant dose arise from medical procedures, the most important contributor being diagnostic radiology [4]. Diagnostic procedures contribute more than $95 \%$ of the medical exposures [5]. There is no safe dose of radiation, as in theory it takes only a single photon or particle to cause damage to DNA resulting in a genetic alteration [6].

Being aware of the harmful effects of radiation, it is necessary to keep the total exposure level as low as consistent with other requirements of practice. In this regard the International Commission on Radiological Protection (ICRP) recommends that medical exposure should be kept as low as reasonably achievable (ALARA) [7].

Reduction of image quality may cause repetition of radiography examination and unnecessary radiation dose to the patient [8]. Optimization in X-ray imaging in order to reduce patient doses during diagnostic radiology examinations is a complex process given the high level of image quality required [9]. In general, the optimization process necessarily requires a balance between patient dose and image quality and it is important that diagnostic quality of the image is not lost in the cause of dose reduction [2]. With that in mind, efforts have been made to assure both the general public and workers that may be exposed to radiation that any exposure they may receive is as low as reasonably achievable-the basis of the ALARA program. However, Images with unacceptable quality can result from 
unwarranted reductions in patient dose. So, patients are often repeatedly exposed to radiation which results in increasing their annual exposure.

Reject/repeat film analysis is a sort of subjective evaluation of image quality where images judged to be of poor quality are categorized according to cause. This program is a useful and well-established method for quality control in diagnostic radiology and provides valuable information about the efficacy of a department [10]. Thus, the objective of reject/repeat analyses is identifying ways to minimize patient exposure and reduce costs. Diagnostic radiology departments would be able to identify potential problem areas, scrutinize the reasons for these problems and come up with ways to rectify them [11].

The ICRP has recommended the use of diagnostic reference levels (DRLs) as a first step in the optimization of diagnostic radiography [12]. With employing DRLs, it is possible to find those hospitals where radiation doses are exceptionally high and where practices may need to be improved [13].

In projection radiography, the assessment of air kerma or dose at the entrance surface of the patient is a common approach to patient dosimetry. Entrance surface air kerma (ESAK) is the air kerma on the central X-ray beam axis at the point where the X-ray beam enters the patient or phantom, which includes the effects of backscatter $[14,15]$. ESAK is recommended by the ICRU for dosimetry in medical imaging. The entrance surface dose (ESD) is defined as the absorbed dose to air at the point of intersection of the X-ray beam axis with the entrance surface of the patient, including backscattered radiation [16]. The United Nations Scientific Committee on the Effect of Atomic Radiation (UNSCEAR) 2008 report uses entrance surface dose for patient dosimetry. ESAK and ESD may be measured using thermoluminescent dosimetry (TLD) but measuring ESD with TLDs is not suitable for routine patient dose assessment. Normally, patient dose is assessed by applying suitable Monte Carlo calculated conversion coefficients to a routinely measured quantity such as ESD [17].

This study is therefore conducted to estimate the patient dose by the use of ESD and dose-area product (DAP) quantities from UNSCEAR 2008 report. So, the aims of this study were: determining dose to the patient from radiographic repeat in Urmia University of Medical Sciences, providing a set of recommendations to reduce the repeat rate and improving the safety culture.

\section{DATA AND METHODS}

In this study, the most frequently examinations were chosen in three radiology centers (Imam Khomeini, Ayatollah Taleghani and Shahid Motahari) of Urmia University of Medical Sciences. Repeat analysis program (RAP) methodology was used in this work [8]. Reject is a useless radiograph and is discarded. Repeat is a radiograph which is retaken to provide further diagnostic information and is sent with the original for reporting. Each of the two contexts in this study considered as repeated radiograph. After a review of the literature, a list of information relevant to repeated radiographs was compiled [18-20]. A form was designed as a repeat analysis form for radiographers to complete each time a film was repeated. The radiographers were informed about the study through a series of presentations. The forms included the following information: type of examination, number and size of film used, number and size of film repeated, reason for repetition, gender and age group (infant ( 0 - 5 years), child (5 - 14 years), adult (14 years and above) [4].

The main reasons for the rejects or repeats is one of the six parameters which categorized in six group; overexposed, under-exposed, position error, patient movement, processor fault and others.

After determining the reason for film repeat as compared to the categories mentioned on the above, these numbers recorded on the repeat analysis form.

The collected data were compiled at the end of each week and entered into a computer for analysis at the end of the study period. The total number of repeated radiographs and the total number of exposed radiographs were determined over a four-month period.

A total of 28657 radiographs from three hospitals were included. The overall repeat rate obtained by dividing the total number of repeated radiographs to the total number of exposed radiographs during the study period. The repeat rate per category was determined by dividing the number of repeats per category to the total number of repeated radiographs.

The DAP value for examination per repeat was used as an indicator of exposure to the patient. The dose-area product has been calculated by multiplying the entrance surface dose per film for the respective selected examination obtained from UNSCEAR report 2008, by the area of the $\mathrm{X}$-ray film size or has been obtained directly from UNSCEAR report 2008 [17]. The dose-area product for intravenous urography (IVU) examination calculated from IAEA report 1996 [21].

The weighted average value of the dose-area product for each examination per repeat and the average value of the dose-area product per repeat were calculated. In this regard the dose-area product was multiplied by the respective percentage of repeats to obtain the weighted average value of the dose-area product for each examination per repeat.

\section{RESULTS}

The distribution of the total number of patients examined as a function of gender showed that in all three hospitals the number of male and female patients were 9634 and 7403 respectively. The Patients' distribution by age 
is also shown in Table $\mathbf{1}$. The results analyzed by examination type are given in Table 2 . The total number of examinations in all three hospitals was 17305 using 28657 radiographs on 16421 patients. This total number included the conventional plain radiography and radiological procedures with contrast media. The total number of repetitions was 2065 of which 263 were for upper limb investtigation, 297 for lower limb, 189 for skull, 312 for spine, 74 for pelvis, 618 for Chest, 70 for plain abdomen, 196 for Gastrointestinal Radiography and 46 for intravenous urography. The highest and lowest repetition rates were for pelvis, $14.01 \%$ and upper limb, $4.17 \%$, respectively. The average repeat rate in all three hospitals was $7.20 \%$. The average number of radiographs used per examination in three hospitals was found to be 1.60 .

Figure 1 shows the distribution of causes for the total number of repeated films in all radiology centers under study. The main reason of repeated radiographs was improper exposure factors. About $54.13 \%$ of all repeated radiographs were due to improper (under/over) exposure.

The analysis of repeated radiographs in Imam Khomeini hospital showed an average repeat rate of $5.84 \%$ with the

Table 1. Patients' distribution by age in all three hospitals.

\begin{tabular}{ccc}
\hline Age group (years) & Number of patients & Percentage \\
\hline $0-5$ & 716 & 4.20 \\
$5-14$ & 2170 & 12.73 \\
$\geq 14$ & 14152 & 83.06 \\
Total & 17038 & 100 \\
\hline
\end{tabular}

highest and lowest repetition for pelvis, $13.46 \%$ and upper limb, 3.7\%, respectively.

The number of radiographs used per examination in this hospital is found to be 1.72 . Table 3 shows the analysis of the repeated radiographs in Imam Khomeini radiology center.

The analysis of repeated radiographs in Ayatollah Taleghani hospital showed an average repeat rate of $9.86 \%$ with the highest and lowest repetition for plain abdomen, $17.95 \%$ and lower limb, $7.80 \%$, respectively. The repeat rates of skull $(17.53 \%)$, pelvis $(14.28 \%)$ and gastrointestinal system (12.04\%) were also significantly high. The number of radiographs used per examination in this hospital is found to be 1.46. Table 4 shows the analysis of the repeated radiographs in Ayatollah Taleghani radiology center.

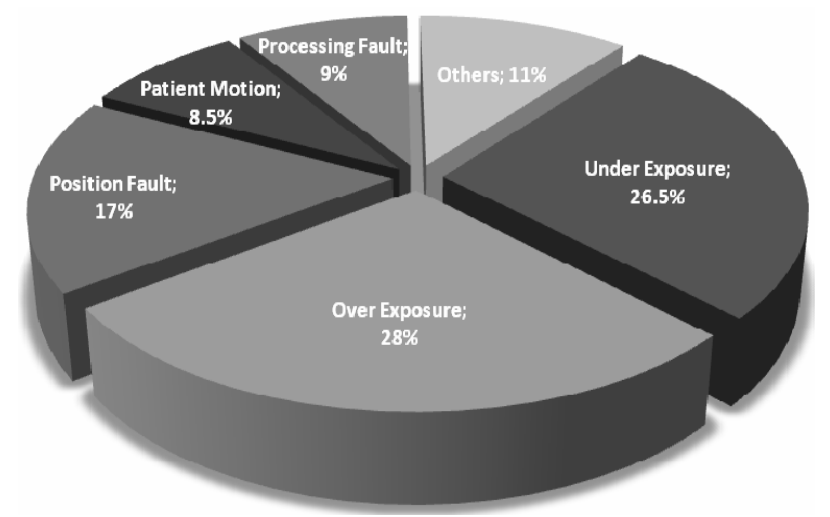

Figure 1. Distribution of causes for the total number of repeated radiographs.

Table 2. Analysis of the repeated radiographs in all three centers.

\begin{tabular}{|c|c|c|c|c|c|c|c|c|c|c|}
\hline Examination & $\begin{array}{l}\text { Number of } \\
\text { Examination }\end{array}$ & $\begin{array}{l}\text { Number of } \\
\text { Radiographs }\end{array}$ & $\begin{array}{l}\text { Under- } \\
\text { exposure }\end{array}$ & $\begin{array}{c}\text { Over- } \\
\text { exposure }\end{array}$ & $\begin{array}{l}\text { Position } \\
\text { fault }\end{array}$ & $\begin{array}{l}\text { Patient } \\
\text { motion }\end{array}$ & $\begin{array}{l}\text { Processing } \\
\text { fault }\end{array}$ & Others & Total & Repeat rate $(\%)$ \\
\hline Upper limb & 4206 & 6310 & 77 & 85 & 31 & 16 & 32 & 22 & 263 & 4.17 \\
\hline Lower limb & 3832 & 5749 & 113 & 59 & 60 & 12 & 24 & 29 & 297 & 5.17 \\
\hline Skull & 1377 & 2548 & 38 & 56 & 39 & 23 & 13 & 20 & 189 & 7.42 \\
\hline Spine & 1614 & 3713 & 78 & 93 & 75 & 19 & 21 & 26 & 312 & 8.40 \\
\hline Pelvis & 352 & 528 & 21 & 21 & 14 & 5 & 5 & 8 & 74 & 14.01 \\
\hline Chest & 4745 & 5695 & 158 & 207 & 78 & 53 & 66 & 56 & 618 & 10.85 \\
\hline Plain abdomen & 406 & 552 & 23 & 14 & 12 & 10 & 6 & 5 & 70 & 12.68 \\
\hline $\begin{array}{l}\text { Gastrointestinal } \\
\text { Radiography }\end{array}$ & 688 & 3079 & 25 & 30 & 38 & 29 & 16 & 58 & 196 & 6.36 \\
\hline $\begin{array}{l}\text { Intravenous } \\
\text { urography }\end{array}$ & 85 & 483 & 13 & 11 & 6 & 7 & 4 & 5 & 46 & 9.52 \\
\hline Total & 17305 & 28657 & 546 & 576 & 353 & 174 & 187 & 229 & 2065 & 7.20 \\
\hline$\%$ Causes for repeat & & & 26.44 & 27.89 & 17.09 & 8.42 & 9.05 & 11.09 & 100 & \\
\hline
\end{tabular}


Table 3. Analysis of the repeated radiographs in Imam Khomeini radiology center.

\begin{tabular}{lcccccccccc}
\hline Examination & $\begin{array}{c}\text { Number of } \\
\text { Examination }\end{array}$ & $\begin{array}{c}\text { Number of } \\
\text { Radiographs }\end{array}$ & $\begin{array}{c}\text { Under- } \\
\text { exposure }\end{array}$ & $\begin{array}{c}\text { Over- } \\
\text { exposure }\end{array}$ & $\begin{array}{c}\text { Position } \\
\text { fault }\end{array}$ & $\begin{array}{c}\text { Patient } \\
\text { motion }\end{array}$ & $\begin{array}{c}\text { Processing } \\
\text { fault }\end{array}$ & Others & Total Repeat rate (\%) \\
\hline Upper limb & 3514 & 5270 & 58 & 70 & 19 & 11 & 26 & 11 & 195 & 3.70 \\
Lower limb & 2805 & 4207 & 81 & 46 & 38 & 4 & 13 & 13 & 195 & 4.63 \\
Skull & 1092 & 2013 & 25 & 44 & 22 & 11 & 4 & 11 & 117 & 5.81 \\
Spine & 1248 & 2865 & 50 & 69 & 55 & 8 & 8 & 15 & 205 & 7.15 \\
Pelvis & 206 & 312 & 14 & 12 & 8 & 2 & 2 & 4 & 42 & 13.46 \\
Chest & 1682 & 2018 & 70 & 80 & 18 & 18 & 25 & 18 & 229 & 11.35 \\
Plain abdomen & 295 & 389 & 14 & 9 & 5 & 5 & 3 & 4 & 40 & 10.28 \\
Gastrointestinal & 498 & 2234 & 12 & 6 & 25 & 12 & 7 & 34 & 96 & 4.30 \\
Radiography & 48 & 283 & 10 & 7 & 2 & 3 & 2 & 2 & 26 & 9.19 \\
Intravenous urography & 11388 & 19591 & 334 & 343 & 192 & 74 & 90 & 112 & 1145 & 5.84 \\
Total & & & 29.17 & 29.96 & 16.77 & 6.46 & 7.86 & 9.78 & 100 \\
\% Causes for repeat & & & & & & & & &
\end{tabular}

Table 4. Analysis of the repeated radiographs in ayatollah Taleghani radiology center.

\begin{tabular}{|c|c|c|c|c|c|c|c|c|c|c|}
\hline Examination & $\begin{array}{l}\text { Number of } \\
\text { Examination }\end{array}$ & $\begin{array}{l}\text { Number of } \\
\text { Radiographs }\end{array}$ & $\begin{array}{l}\text { Under- } \\
\text { exposure }\end{array}$ & $\begin{array}{c}\text { Over- } \\
\text { exposure }\end{array}$ & $\begin{array}{l}\text { Position } \\
\text { fault }\end{array}$ & $\begin{array}{l}\text { Patient } \\
\text { motion }\end{array}$ & $\begin{array}{l}\text { Processing } \\
\text { fault }\end{array}$ & Others & Total & Repeat rate $(\%)$ \\
\hline Upper limb & 205 & 307 & 7 & 4 & 6 & 1 & 2 & 5 & 25 & 8.14 \\
\hline Lower limb & 342 & 513 & 13 & 3 & 11 & 3 & 4 & 6 & 40 & 7.80 \\
\hline Skull & 84 & 154 & 5 & 3 & 9 & 4 & 3 & 3 & 27 & 17.53 \\
\hline Pelvis & 56 & 84 & 2 & 3 & 3 & 1 & 1 & 2 & 12 & 14.28 \\
\hline Chest & 2210 & 2650 & 56 & 75 & 48 & 21 & 18 & 21 & 239 & 9.02 \\
\hline Plain abdomen & 50 & 78 & 4 & 2 & 4 & 3 & 1 & 0 & 14 & 17.95 \\
\hline $\begin{array}{l}\text { Gastrointestinal } \\
\text { Radiography }\end{array}$ & 97 & 432 & 7 & 15 & 7 & 9 & 3 & 11 & 52 & 12.04 \\
\hline Total & 3256 & 4754 & 111 & 119 & 100 & 49 & 37 & 53 & 469 & 9.86 \\
\hline$\%$ Causes for repeat & & & 23.67 & 25.37 & 21.32 & 10.45 & 7.89 & 11.30 & 100 & \\
\hline
\end{tabular}

The analysis of repeated radiographs in Shahid Motahari hospital showed an average repeat rate of $10.50 \%$. The highest repeat rate of $18.82 \%$ was observed for plain abdomen examination. This may be due to this fact that the relative frequency of this examination is the lowest. The repeat rates of pelvis $(15.91 \%)$, chest $(14.60 \%)$ and spine $(13.57 \%)$ were also significantly high. The number of radiographs used per examination in this hospital is found to be 1.62. Table 5 shows the analysis of the repeated radiographs in Shahid Motahari radiology center.

Table 6 shows the evaluation of the average value of the dose-area product per repeat and the weighted average value of the dose-area product for each examination per repeat.

\section{DISCUSSION AND CONCLUSIONS}

An analysis of radiographic repeat data in this study showed an average repeat rate of $7.20 \%$. The previous studies reported that the typical values of repeat rates were $3.5 \%$ to $19.3 \%[3,6,22]$. From the information acquired by the methodology, it is obvious that the main reason for radiographic repeat is a function of multi parameters, such as working experience of the personnel, workload of the radiology center, using automatic exposure control system (photo timers), etc. The results of this study showed that the main reasons of repetition of radiographs are due to exposure $(54 \%)$ and positioning $(18 \%)$ errors. It was found that human error has important role to these causes. 
Table 5. Analysis of the repeated radiographs in Shahid Motahari radiology center.

\begin{tabular}{|c|c|c|c|c|c|c|c|c|c|c|}
\hline Examination & $\begin{array}{l}\text { Number of } \\
\text { Examination }\end{array}$ & $\begin{array}{c}\text { Number of } \\
\text { Radiographs }\end{array}$ & $\begin{array}{l}\text { Under- } \\
\text { exposure }\end{array}$ & $\begin{array}{l}\text { Over- } \\
\text { exposure }\end{array}$ & $\begin{array}{l}\text { Position } \\
\text { fault }\end{array}$ & $\begin{array}{l}\text { Patient } \\
\text { motion }\end{array}$ & $\begin{array}{l}\text { Processing } \\
\text { fault }\end{array}$ & Others & Total & Repeat rate $(\%)$ \\
\hline Upper limb & 487 & 733 & 12 & 11 & 6 & 4 & 4 & 6 & 43 & 5.87 \\
\hline Lower limb & 685 & 1029 & 19 & 10 & 11 & 5 & 7 & 11 & 63 & 6.12 \\
\hline Skull & 201 & 381 & 8 & 9 & 8 & 8 & 6 & 6 & 45 & 11.81 \\
\hline Spine & 168 & 398 & 13 & 11 & 10 & 5 & 8 & 7 & 54 & 13.57 \\
\hline Pelvis & 90 & 132 & 5 & 6 & 3 & 2 & 2 & 3 & 21 & 15.91 \\
\hline Chest & 853 & 1027 & 32 & 52 & 12 & 14 & 23 & 17 & 150 & 14.60 \\
\hline Plain abdomen & 61 & 85 & 5 & 3 & 3 & 2 & 2 & 1 & 16 & 18.82 \\
\hline Intravenous urography & 23 & 117 & 1 & 3 & 2 & 3 & 2 & 2 & 13 & 11.11 \\
\hline Total & 2661 & 4315 & 101 & 114 & 61 & 51 & 60 & 66 & 453 & 10.50 \\
\hline$\%$ reasons for repeat & & & 22.29 & 25.16 & 13.46 & 11.26 & 13.24 & 14.57 & 100 & \\
\hline
\end{tabular}

Table 6. Patient dose per film and per repeat for each examination in all three hospitals.

\begin{tabular}{|c|c|c|c|c|c|}
\hline Examination & $\begin{array}{l}\text { Percent of } \\
\text { repeat rate }\end{array}$ & Film size $\left(\mathrm{cm}^{2}\right)$ & $\begin{array}{l}\text { Average ESDs per } \\
\text { radiograph (mGy) }\end{array}$ & $\begin{array}{c}\text { Average DAP per } \\
\text { radiograph }\left(\mathrm{Gy} \cdot \mathrm{cm}^{2}\right)\end{array}$ & $\begin{array}{c}\text { Weighted average } \\
\text { value of DAP per repeat }\left(\mathrm{Gy} \cdot \mathrm{cm}^{2}\right)\end{array}$ \\
\hline Upper limb & 12.74 & $24 \times 30$ & 0.38 & 0.27 & 0.034 \\
\hline Lower limb & 14.38 & $24 \times 30$ & 0.96 & 0.68 & 0.098 \\
\hline Skull & 9.15 & $24 \times 30$ & 1.95 & 1.40 & 0.128 \\
\hline Lumbar spine & 15.11 & $30 \times 40$ & 10.25 & 2.85 & 0.431 \\
\hline Pelvis & 3.58 & $35 \times 42.5$ & 2.18 & 2.6 & 0.093 \\
\hline Chest & 29.93 & $35 \times 35$ & 0.55 & 0.67 & 0.200 \\
\hline Plain abdomen & 12.88 & $35 \times 42.5$ & 5.4 & 3.1 & 0.400 \\
\hline Intravenous urography (IVU) & 2.23 & $30 \times 40$ & 8.76 & 10.51 & 0.234 \\
\hline
\end{tabular}

These results are consistent with previous studies which reported that exposure and patient positioning errors are the main reasons for repeat of examinations $[3,6,9,23]$. Repetition due to exposure error considered as over-exposure and under-exposure. Over-exposure gives a dark film with decreased resolution and under-exposure results in soft film and drop out the detail. So, accurate exposure is one of the important factors providing a good quality image with high resolution.

In this study the average number of radiographs used per examination was 1.60. This value is lower than most of the published values, which range from 2.4 to 4.0 radiographs per examination [24,25] and higher than the value obtained (1.5 radiographs per examination) by Al-
Malki et al. [3]. The number of radiographs used per examination in the Imam Khomeini hospital is relatively higher than the other two hospitals. It seems, this is related to this fact that the Imam Khomeini hospital is an emergency and trauma hospital.

The main objective of this study was to determine the patient dose from radiographic repeats. As we have shown, the radiographic repeat rate $(7.20 \%)$ in all three hospitals involved $6.17 \%$ of patients. This led them to have an average of 1.17 additional radiographs. Based on the average value of the dose-area product per repeat $\left(2.76 \mathrm{~Gy} \cdot \mathrm{cm}^{2}\right)$, we can conclude that those patients having repeated radiographs received an average of $3.23 \mathrm{~Gy} \cdot \mathrm{cm}^{2}$. This average value is lower than that obtained by Al-Malki et al. 
[3]. This has been caused by the use of small film sizes and low value of average repeat rate in this study. In addition, the average value is lower than that obtained by Mustafa et al [26]. It can be due to the use of updated [17] values of exposure per radiograph that are relatively lower except chest. The values used by the Mustafa for chest, abdomen and lumbar spine were 0.26, 6.41 and $8.84 \mathrm{mGy}$ per radiograph. While the average values used in this study are $0.55,5.4$ and $10.25 \mathrm{mGy}$ per radiograph respectively.

So, in comparison with earlier studies the results from this current work indicate a continuing downward trend in doses for most of the common radiographs and examinations studied. In this regard the mean ESDs showed a distinct downward trend with time for all types of radiographs except chest. The mean ESD for PA chest radiographs showed an insignificant reduction between NRPB repot 2000 ( $0.15 \mathrm{mGy})$ [27] and this study $(0.17 \mathrm{mGy})$ from UNSCEAR report 2008 [17]. For lateral chest radiographs there was an apparent increase between NRPB repot 2000 $(0.85 \mathrm{mGy})$ and those used in this study (0.94 mGy) [17]. The average dose-area product value for IVU examination $\left(10.51 \mathrm{~Gy} \cdot \mathrm{cm}^{2}\right)$ was almost the same as the value obtained by Muller et al $\left(10.17 \mathrm{~Gy} \cdot \mathrm{cm}^{2}\right)[28]$.

Typical the average dose for common radiographic examinations have dropped. There is evidence that this reduction is partly due to the use of faster film-screen combinations and it may also have been assisted by the observed increase in the use of modern digital imaging equipment.

The results obtained by this study showed that the highest repetition rate was for pelvis $(14.01 \%)$. It is documented that the pelvic region contains some of the most radiosensitive organs in the body [29]. The UNSCEAR report 2008, states that the average dose that a patient receives from a pelvic X-ray is $2.18 \mathrm{mGy}$ [17]. Considering the radiosensitive organs related to pelvis and patient dose received from a pelvis examination, this repeat rate is high. So, some special considerations must be applied for pelvis and abdomen examinations.

It may be noted that one way to enforce the ALARA principle within radiography centers is through a properly conducted repeat analysis. The current work demonstrated that the infant and children groups of this study involved nearly $17 \%$ of patients. The most of these group patients are belong to the Shahied Motahari hospital which is a maternity and children hospital. Reports from Committee on the Biological Effects of Ionizing Radiation and ICRP $[7,30]$ show that children are clearly more sensitive to radiation than adults as they have more dividing cells which radiation can affect [31]. Children, therefore, need more careful evaluation with regard to the necessity of examination, and the radiographic technique needs to be more exacting. It must be remembered that the gonads and bone marrow protection are of major importance in pediatric patients.
Finally, it was said that the main objective of x-ray examination is to obtain optimum diagnostic information with minimum diagnostic exposure. This can be achieved by giving careful consideration to the use of X-ray equipment, its design and how the procedure is performed. This study pointed out that the repeat rate in the Shahied Motahari hospital is relatively higher compared to other hospitals. This hospital is dedicated to infants, children and women. So, it seems that the application of some special considerations for this radiology department is necessary.

The results obtained by this repeat analysis study provided valuable information to suggest preventive measures to reduce repeats. In this regard the following recommendations are prescribed for the radiology department to reduce the repeat rate and to improve the radiation safety culture.

1) Use of ALARA principles

2) Implementation of quality assurance and quality control programs of imaging

3) Implementation of repeat analysis program periodically

4) Avoid the use of grids whenever possible

5) Use of additional filtration

6) Use of high-voltage technique

7) Use of short time exposure

8) Use of high-speed screen-film system

9) Use of proper dark room conditions and procedures

10) Doing the job distribution of the technical staff carefully to reduce human error.

We hope this work will contribute to an improvement of the safety culture and QA program of the concerned hospitals and finally will contribute to reduce the rate of repeats.

\section{REFERENCES}

[1] Bushberg, J.T., Seibert, J.A., Leidholdt, E.M. and Boone, J.M. (2002) The essential physics of medical imaging. Lippincott Williams and Wilkins, Philadelphia.

[2] Australian Radiation Protection and Nuclear Safety Agency (2008) Radiation protection in diagnostic and interventional radiology. Radiation Protection Series Publication No. 14.1, Victoria.

[3] Bassey, C.E., Ojo, O.O. and Akpabio, I. (1991) Repeat profile analysis in an x-ray department. Journal of Radiological Protection, 11, 179-183.

[4] Al-Malki, M.A., Abulfaraj, W.H., Bhuiyan, S.I. and Kinsara, A.A. (2003) A study on radiographic repeat rate data of several hospitals in Jeddah. Radiation Protection Dosimetry, 103, 323-330.

[5] Supe, S.J., Lyer, P.S., Sasane, J.B., Sawant, S.G. and Shirva, V.K. (1992) Estimation and significance of patient doses from diagnostic X-ray practices in India. Radiation Protection Dosimetry, 43, 209-211.

[6] Canon, C.L. (2010) McGraw-Hill specialty board review 
radiology. McGraw-Hill Companies, New York.

[7] International Commission on Radiological Protection (1991) Recommendations of the international commission on radiological protection. ICRP Publication 60, Oxford.

[8] Shabestani Monfared, A., Abdi, R. and Saber, M.A. (2007) Repeat analysis program in radiology departments in Mazandaran province-Iran; impact on population radiation dose. Iranian Journal of Radiation Research, 5, 3740.

[9] Sniureviciute, M. and Adliene, D. (2005) Problems with film processing in medical X-Ray imaging in Lithuania. Radiation Protection Dosimetry, 5, 260-263. doi:10.1093/rpd/nch577

[10] Lau, S.L., Mak, A.S., Lam, W.T., Chau, C.K. and Lau, K.Y. (2004) Reject analysis: A comparison of conventional filmescreen radiography and computed radiography with PACS. Radiography, 10, 183-187. doi:10.1016/j.radi.2004.03.014

[11] Zewdeneh, D., Teferi, S. and Admassie, D. (2008) X-ray reject analysis in Tikur Anbessa and Bethzatha Hospitals. Ethiopian Journal of Health Development, 22, 63-97.

[12] International Commission on Radiological Protection (1996) Radiological protection and safety in medicine. ICRP Publication, Oxford.

[13] Kiljunen, T., Jarvinen, H. and Savolainen, S. (2007) Diagnostic reference levels for thorax X-ray examinations of paediatric patients. The British Journal of Radiology, 80, 452-459. doi:10.1259/bjr/60918774

[14] International Atomic Energy Agency (2007) Dosimetry in diagnostic radiology. International code of practice. IAEA Technical Reports Series No. 457, Vienna.

[15] International Commission on Radiation unites and measurements (1998) Fundamental quantities and unites for ionizing radiation. ICRU Report 60.

[16] Duggan, L., Warren-Forward, H., Smith, T. and Kron, T. (2003) Investigation of dose reduction in neonatal radiography using specially designed phantoms and LiF:Mg, $\mathrm{Cu}, \mathrm{P}$ TLDs. The British Journal of Radiology, 76, 232237. doi:10.1259/bjr/79291075

[17] United Nations Scientific Committee on the Effect of Atomic Radiation (2008) Sources and effects of ionizing radiation. UNSCEAR Report 2008.

[18] Watkinson, S., Moores, M. and Hill, S.J. (1994) Reject analysis: Its role in quality assurance. Radiography, 50, 189-194.

[19] Dunn, M.A. and Rogers, A.T. (1998) X-ray film reject analysis as a quality indicator. Radiography, 4, 29-31.

\section{doi:10.1016/S1078-8174(98)80027-8}

[20] Koichi, C., Mamoru, K., Yutaka, K., et al. (2010) Radiation dose and radiation protection for patients and physicians during interventional procedure. Journal of Radiation Research, 51, 97-105. doi:10.1269/jrr.09112

[21] International Atomic Energy Agency (1996) International basic safety standards for protection against ionizing radiation and for the safety of radiation source. IAEA Safety Series No. 115, Vienna.

[22] Nixon, P.P., Thorogood, J., Holloway, J. and Smith, N.J. (1995) An audit of film reject and repeat rates in a department of dental radiology. The British Journal of Radiology, 68, 1304-1307. doi:10.1259/0007-1285-68-816-1304

[23] Peer, S., Peer, R., Walcher, M., Pohl, M. and Jaschke, W. (1999) Comparative reject analysis in conventional film screen and digital storage phosphor radiography. European Radiology, 9, 1693-1696.

[24] Chu, W.K., Ferguson, S., Wunder, B., Smith, R. and Vanhoutte, J.J. (1982) A Two-year reject/retake profile analysis in paediatric radiology. Health Physics, 42, 53-59. doi:10.1097/00004032-198201000-00005

[25] Adler, A., Carlton, R. and Wold, B. (1992) An analysis of radiographic repeat and reject rates. Radiologic Technology, 63, 308-314.

[26] Mustafa, A.A., Vasisht, C.M. and Sumarasekara, S.J. (1987) Analysis of wasted X-ray films: Experience in two Kuwait hospitals. The British Journal of Radiology, 60, 513-515. doi:10.1259/0007-1285-60-713-513

[27] Hart, D., Hillier, M.C. and Wall, B.F. (2000) Doses to patients from medical X-ray examinations in UK. NRPBW14, Chilton

[28] Müller, M., Heicappell, R., Steiner, U., Merkle, E., Aschoffm, A.J. and Miller, K. (1998) The average dose-area product at intravenous urography in 205 adults. The British Journal of Radiology, 71, 210-212.

[29] Clark, P.A. and Hogg, P. (2003) Reject/repeat analysis and the effect prior film viewing has on a department's reject/repeat rate. Radiography, 9, 127-137. doi:10.1016/S1078-8174(03)00036-1

[30] Committee on the Biological Effects of Ionizing Radiation (1990) Health effects of exposure to low levels of ionizing radiation. BEIR V, Washington DC.

[31] McEntee, M.F. and Kinsella, C. (2010) An examination of practice during radiography of the clavicle. Radiography, 16, 125-130. doi:10.1016/j.radi.2009.12.002 